\title{
Taxa de concepção de éguas submetidas a duas frequências de palpação retal (24 e 12 horas) e cobertas após a ovulação
}

\section{Conception rate of mares controlled by two rectal palpation intervals (24 or $12 \mathrm{~h}$ ) and breeding after ovulation}

\author{
Fernando Andrade Souza, ${ }^{*}$ Álan Maia Borges, ${ }^{* *}$ José Monteiro Silva Filho, ${ }^{* *}$ Maristela Silveira Palhares, ${ }^{* *}$ Walmir Santos \\ Viana, ${ }^{* * *}$ Guilherme Pugliesi, ${ }^{* * * *}$ Camila Haddad Oliveira, ${ }^{* * * *}$ Raissa Rossi ${ }^{* * * *}$
}

\begin{abstract}
Resumo
Este trabalho foi realizado com o objetivo de estudar a fertilidade de éguas cobertas após a ovulação, segundo um manejo de palpação retal a cada 24 (P1) ou 12 horas (P2), e cobertas por dois garanhões (G1 e G2). O estudo utilizou 84 ciclos estrais de 50 éguas mestiças do tipo militar, distribuídos ao acaso, segundo um esquema fatorial $2 \times 2$. A taxa de gestação para o primeiro, segundo e terceiro ciclos estrais foram de: $29,41 \%$ (5/17) e $50 \%(4 / 8)$ para o grupo P1G1; $25 \%(5 / 20), 54,54 \%$ (6/11) e 100\% (2/2) para o grupo P2G1; 41,66\% (5/12) e 50\% (2/4) para o grupo P1G2; e de 60\% (6/10) para o grupo P2G2, respectivamente. A taxa de gestação total/ciclo, para cada um dos quatro tratamentos, foi de $36 \%(9 / 25), 39,40 \%(13 / 33)$, $43,75 \%(7 / 16)$ e $60 \%(6 / 10)$, respectivamente. A taxa de concepção por ciclo estral não diferiu $(p>0,05)$, pelo teste Exato de Fisher. Assim, os dados foram reagrupados levando-se apenas em consideração a freqüência de palpação retal, e obteve-se $39,02 \%$ (16/41) e 44,19\% (19/43) de taxa de concepção/ciclo e 55,20\% (16/29) e 63,30\% (19/30) de taxa de concepção total para os intervalos de palpação de 24 e 12 horas, respectivamente.
\end{abstract}

Palavras-chave: cobertura pós-ovulação, eqüinos, monta natural, taxa de concepção.

\begin{abstract}
The objective of the experiment was to study the fertility of mares bred after ovulation, detected by rectal palpation every 24 (P1) or 12 hours (P2), using two stallions (G1 and G2). This study was done with 84 estrus cycles of 50 military crossbred mares, randomly assigned to four treatments. The conception rate for first, second and third estrus cycles were $29.41 \%(5 / 17)$ and $50.00 \%$ (4/8) for group P1G1; $25.00 \%$ (5/20), 54.54\% (6/11) and $100.00 \%(2 / 2)$ for group P2G1; $41.66 \%(5 / 12)$ and $50.00 \%(2 / 4)$ for group P1G2; and $60.00 \%$ (6/10) for group P2G2, respectively. The conception rate for each treatment were $36.00 \%(9 / 25)$, $39.40 \%$ (13/33), 43.75\% (7/16) and 60.00\% (6/10). The conception rate by estrus cycle did not differ $(p>0.05)$ by Fisher Test. The data obtained were regrouped considering only the rectal palpation frequency and it was obtained $39.02(16 / 41)$ and $44.19 \%$ (19/43) for conception rate by estrus cycle and 55.20\% (16/29) and 63.30\% (19/30) for total conception rate for 24 and 12 to rectal palpation intervals, respectively.
\end{abstract}

Keywords: conception rate, equine, natural breeding, post ovulation breeding.

\section{Introdução}

A determinação do dia ou momento da ovulação poderá ter considerável impacto na coordenação do momento da cobertura, tanto por monta natural quanto por inseminação artificial. Isto permite maximizar o uso do garanhão, diminuindo o risco de contaminação uterina, por reduzir a quantidade de inseminações ou montas por ciclo estral, além de propiciar melhor manejo para as éguas susceptíveis à endometrite (iRoig et al., 2005).
Na espécie eqüina, a fase folicular é altamente variável e inconsistente, o que torna difícil a determinação do final do estro, dificultando a predição do momento da ovulação. Contudo, o exame contínuo, com quatro ou seis horas de intervalo, durante o período do estro poderá predizer, com relativa confiabilidade, o momento da ovulação das éguas (iRoig et al., 2005). O intervalo de palpações freqüentes gera grandes desgastes aos animais e ao médico-veterinário responsável pelo manejo reprodutivo. Porém, este tipo de manejo freqüente de palpação possibilita a cobertura da égua

* Doutorando Ciência Animal - Universidade Federal de Minas Gerais.

** Professor adjunto do departamento de Clínica e Cirurgia - Universidade Federal de Minas Gerais.

*** Regimento de Cavalaria Alferes Tiradentes - Polícia Militar de Minas Gerais.

**** Mestrando em Zootecina - Universidade Federal de Viçosa.

${ }^{* * * \star}$ Mestre em Ciência Animal - Universidade Federal de Minas Gerais.

Endereço para correspondência: Rua Noraldino de Lima, no 265, Apt. 11, Pampulha, 31270-650, Belo Horizonte-MG.

E-mail: femedvet@yahoo.com.br 
o mais próximo da ovulação, de forma que tanto o gameta masculino quanto o feminino estejam viáveis no momento da fecundação (Jacob et al. 2000). Isto porque o oócito, após ser liberado, possui período muito curto de sobrevivência, quando comparado às células espermáticas (Hunter, 1990).

Alguns autores citam que a viabilidade do oócito perdura por até 12 horas, após ser liberado (Palmer, 1984). Como o tempo de viabilidade do oócito depende do seu estádio de desenvolvimento no momento da ovulação, os oócitos fecundados 12 e 24 horas após serem ovulados podem gerar taxa de concepções similares às encontradas para coberturas realizadas próximas ao momento da ovulação (Hunter, 1990).

O presente experimento objetivou determinar a taxa de fertilidade de éguas mestiças cobertas, por monta natural após a ovulação, seguindo-se o manejo de palpação retal a cada 12 ou 24 horas.

\section{Material e métodos}

\section{Localização, condições climáticas e período experimental}

O experimento foi realizado em dois períodos: 1) De outubro a dezembro de 2005, nas instalações da sede do Regimento de Cavalaria Alferes Tiradentes (RCAT), da Polícia Militar do estado de Minas Gerais, no município de Belo Horizonte, localizado na região da Zona Metalúrgica do Estado de Minas Gerais, situado a $19^{\circ} 55^{\prime} 15^{\prime \prime}$ de latitude $S$ e $43^{\circ} 56^{\prime} 16^{\prime \prime}$ de longitude W Gr., a uma altitude média de $832 \mathrm{~m}$ e clima do tipo Cwa, de acordo com a classificação de Köeppen, ou seja, inverno seco e verão chuvoso; e 2) De janeiro a março de 2006, nas dependências do Núcleo Eqüino de Reprodução (NER), também pertencente ao RCAT, no município de Florestal, no estado de Minas Gerais, localizado a 19 $56^{\prime} 15^{\prime \prime}$ de latitude S e $44^{\circ} 26^{\prime} 15^{\prime \prime}$ de longitude W Gr., a uma altitude aproximada de 500m acima do nível do mar e clima tipo Cwa.

\section{Delineamento experimental}

Foram utilizados 84 ciclos estrais de 59 éguas mestiças do tipo militar. Os animais foram agrupados e uniformizados segundo a idade, categoria (potras, éguas solteiras ou éguas com potro ao pé) e data do parto. As éguas foram distribuídas ao acaso em dois grupos (P1 e P2) de intervalos de palpação a cada 24 ou 12 horas para cada garanhão (G1 e G2), com número desigual de repetições, seguindo um esquema fatorial $2 \times 2$, considerando-se o efeito dos dois sistemas de palpação transretal e dos dois garanhões, como descritos a seguir: éguas palpadas uma vez por dia (P1) e cobertas, após a detecção da ovulação, pelo garanhão G1 - P1G1 (17 éguas); éguas palpadas duas vezes por dia (P2) e cobertas, após a detecção da ovulação, pelo garanhão G1 - P2G1 (20 éguas); éguas palpadas uma vez por dia (P1) e cobertas, após a detecção da ovulação, pelo garanhão G2 - P1G2 (12 éguas); éguas palpadas duas vezes ao dia (P2) e cobertas, após a detecção da ovulação, pelo garanhão G2 - P2G2 (10 éguas).

\section{Animais e manejo experimental}

\section{Éguas}

Utilizaram-se éguas com idade variando de quatro a 24 anos, com escore da condição corporal médio igual a três (escala 1 a 5), onde o escore 1 refere-se aos animais extremamente magros e 05 aos obesos. Antes do início da estação de monta, as éguas foram submetidas a exame ginecológico por meio de ultra-sonografia e palpação transretal, avaliando-se as características da genitália externa e interna. A partir destes exames, foram diagnosticados problemas reprodutivos (cistos endometriais e acúmulo anormal de líquido intrauterino) em 13 éguas que, então, foram agrupadas e alocadas, por meio de sorteio, entre os quatro grupos experimentais, já descritos. Nenhuma égua que tenha apresentado problema quanto à higidez uterina foi descartada, e todos os ciclos foram contabilizados e utilizados nas análises estatísticas.

As éguas foram palpadas e rufiadas individualmente, a cada três dias, até o início do cio e/ou da presença de um folículo de 2,0-2,5cm de diâmetro, presente em um dos ovários. A partir daí, as palpações retais e as rufiações tornaram-se diárias até o momento da ovulação. Após a detecção da ovulação os animais foram cobertos por monta natural após a higienização do períneo das éguas, com água e sabão de coco, seguida de secagem com papel-toalha, bandagem da cauda e contenção das mesmas para que não houvesse 0 risco de lesão ao garanhão e ao médico-veterinário.

Após a cobertura, as éguas foram mantidas afastadas do controle folicular diário, até o momento da rufiação de retorno, realizado entre o $15^{\circ}$ e 0 21ำ dia após a ovulação. O diagnóstico de gestação foi feito por palpações transretais nos dias 17 , $25,30,35,40,45,60$ e 90 após a ovulação. Os animais diagnosticados positivos tinham a gestação confirmada por ultra-sonografia transretal. Para a rufiação utilizou-se um macho inteiro, sem raça definida, submetido à amputação da glande. As éguas com diagnóstico negativo de gestação voltavam para o mesmo tratamento, de acordo com os intervalos de palpação previamente estabelecidos.

O manejo nutricional consistiu no fornecimento diário de cerca de $10 \mathrm{~kg}$ de capim elefante (Pennisetum purpureum, Schum.) picado, $2 \mathrm{~kg}$ de feno de alfafa (Medicago sativa, L.), $3 \mathrm{~kg}$ de ração comercial peletizada, ${ }^{1}$ sal mineralizado ${ }^{2}$ e água ad libitum. Os animais alojados no RCAT foram mantidos em baias de alvenaria medindo cerca de $4,5 \mathrm{~m}^{2}$, com piso cimentado e cama de serragem, durante a maior parte do dia e à noite. Na estação de Florestal (NER), as éguas recebiam o mesmo manejo nutricional. No entanto, ficavam alojadas em piquetes de capim Brachiaria brizantha.

\section{Garanhões}

Foram utilizados, para monta natural, dois garanhões (G1 e G2) da raça Brasileira de Hipismo, com idades de 21 e 18 anos, respectivamente. Antes do início da estação de monta, os garanhões foram submetidos a exame andrológico com inspeção e palpação da genitália externa, avaliação do comportamento sexual, bem como pela avaliação física e morfológica do sêmen. Ao exame físico do sêmen, no início da estação de monta, os dois garanhões apresentaram quadro espermático condizente com o histórico de repouso sexual, melhorando-se o perfil após o esgotamento das reservas espermáticas extragonadais, realizadas por meio de coletas diárias, durante sete dias consecutivos. Desta forma, foi demandada sua utilização e, então, considerados

\footnotetext{
${ }^{1}$ Nutriage ${ }^{\circledR}-$ Guabi.

2 Centauro® - Guabi.
} 
aptos à experimentação, segundo as recomendações de Pickett et al. (1987).

Quanto ao manejo nutricional, os garanhões alojados na estação de monta de Belo Horizonte (RCAT) recebiam, diariamente, cerca de $10 \mathrm{~kg}$ de capim elefante picado (Pennisetum purpureum, Schum.), cerca de $3 \mathrm{~kg}$ de feno de alfafa (Medicago sativa, L.), $3 \mathrm{~kg}$ de ração comercial peletizada, ${ }^{3}$ sal mineral ${ }^{4}$ e água ad libitum. Os animais permaneciam totalmente confinados em baias de alvenaria de $9 \mathrm{~m}^{2} \mathrm{com}$ piso cimentado, recoberto por cama de serragem, sendo retirados apenas nos momentos de cobertura das éguas.

\section{Análise estatística}

As análises estatísticas foram realizadas utilizando-se o programa S.A.S., ${ }^{5}$ por meio da aplicação de um modelo que inclui os efeitos fixos do intervalo de palpações, do garanhão e a interação dessas variáveis sobre as variáveis quantitativas. Os dados proporcionais como taxa de concepção/ciclo estral e taxa de concepção total foram submetidos ao Teste de Exato de Fisher. Para as variáveis quantitativas aplicou-se a análise GLM (General Linear Model - S.A.S. ${ }^{5}$ ) para que pudesse ser retirado o efeito das parcelas perdidas. Para a comparação de mais de duas médias utilizou-se o Teste de StudentNewman-Keuls (SNK), sendo o Teste t de Student utilizado na comparação de duas médias.

\section{Resultados e discussão}

\section{Número de ciclos estrais por égua, por égua vazia e égua gestante}

O presente estudo obteve, seguindo a prerrogativa da utilização de apenas uma cobertura por ciclo estral após o diagnóstico da ovulação, os valores de 1,32 $\pm 0,48,1,45 \pm$ $0,62,1,25 \pm 0,45$ e 1,00 $\pm 0,00$ ciclos estrais/égua para os tratamentos P1G1, P2G1, P1G2 e P2G2, respectivamente (Tabela 1), encontrando-se diferenças $(p<0,05)$ apenas entre os tratamentos P2G1 e P2G2.
A diferença $(p<0,05)$ encontrada entre os tratamentos P2G1 e P2G2 para o número de ciclos estrais/égua e número de ciclos estrais/égua gestante, pode ser considerada aleatória. A diferença entre estes dois tratamentos ocorreu devido ao tratamento P2G1 ter gerado maior número de ciclos estrais, dentre todos os tratamentos. Em contra partida, o tratamento P2G2 gerou o menor número de ciclos. Como a distribuição das unidades experimentais dentro de garanhões foi aleatória e uniforme, e esta diferença só foi determinada entre estes dois tratamentos, podemos considerá-la como ao acaso.

Os resultados obtidos no presente estudo foram semelhantes aos dados encontrados por Belling (1984) que, compilando os resultados de sete anos de trabalho a campo, em 12 fazendas localizadas nos estados do Novo México, Texas e Flórida, obteve por meio da cobertura de 355 éguas, dentro de um período de até 24 horas pós-ovulação, uma taxa de 1,45 serviços/concepção, variando entre 1,0 e 1,56, que gerou taxa total de 68\% (293/425).

Em um trabalho semelhante ao aqui apresentado, Silva (1995) trabalhou com dois garanhões realizando coberturas até 6 horas após a ovulação de 33 éguas mestiças, e obteve 2,33 e 1,80 ciclos/égua e 2,07, 1,33 ciclos/égua gestante, para os garanhões 1 e 2, respectivamente. Na mesma ordem anterior, Silva (1995), no mesmo trabalho, cobrindo 34 éguas até 12 horas após a ovulação, obteve 1,58 e 2,41 ciclos/égua e 1,37 e 1,92 ciclos estrais/égua gestante, demonstrando não haver diferença entre os tratamentos.

Os dados da literatura científica, quanto à cobertura por monta natural, que avaliam estas variáveis são escassos, assim, limitando a comparação com os resultados aqui expostos. Entretanto, dentro dos trabalhos que expõem a exeqüibilidade das coberturas após a ovulação, todos são unânimes em ressaltar que o menor número de coberturas por ciclo, neste tipo de tratamento, permite melhor condição uterina da égua e, com isto, favorecem a menor taxa de ciclos, tanto por égua gestante quanto por égua vazia.

Os valores aqui obtidos têm implicações práticas e econômicas no sistema de produção animal que, atualmente,

Tabela 1: Parâmetros reprodutivos e de controle de éguas mestiças submetidas a duas freqüências de palpação retal (24 e 12 horas) e cobertas por dois garanhões

\begin{tabular}{|c|c|c|c|c|}
\hline \multirow[t]{2}{*}{ Parâmetros avaliados } & \multicolumn{2}{|c|}{ Intervalo de Palpações para Garanhão } & \multicolumn{2}{|c|}{$\begin{array}{c}\text { Intervalo de Palpações para } \\
\text { Garanhão } 2\end{array}$} \\
\hline & 24 horas (P1G1) & 12 horas (P2G1) & 24 horas (P1G2) & 12 horas (P2G2) \\
\hline № de Éguas & 17 & 20 & 12 & 10 \\
\hline № de Ciclos & 25 & 33 & 16 & 10 \\
\hline $\begin{array}{l}\text { № de Ciclo/ Égua } \\
\text { № de Ciclo/Égua vazia } \\
\text { № de Ciclo/Égua Gestante } \\
\text { Idade das Éguas } \\
\text { Intervalo de Palpação (h) } \\
\text { Intervalo de Palpação/Cobertura } \\
\text { Taxa Concepção/Ciclo (\%) } \\
\text { Eficiência de Prenhez } \\
\text { Perda Gestacional (\%) }\end{array}$ & $\begin{array}{c}1,32 \pm 0,48^{\mathrm{a}, \mathrm{b}} \\
1,25 \pm 0,45 \\
1,44 \pm 0,53^{\mathrm{a}, \mathrm{b}} \\
104,56 \pm 47,46^{\mathrm{a}} \\
23,45 \pm 2,23^{\mathrm{a}} \\
1,04 \pm 0,79 \\
36,00(9 / 25) \\
3,28 \pm 4,50 \\
11,10(1 / 9) \\
\end{array}$ & $\begin{array}{c}1,45 \pm 0,62^{\mathrm{a}} \\
1,25 \pm 0,44 \\
1,77 \pm 0,73^{\mathrm{a}} \\
116,73 \pm 65,80^{\mathrm{a}, \mathrm{b}} \\
12,66 \pm 2,40^{\mathrm{b}} \\
1,09 \pm 0,66 \\
39,40(13 / 33) \\
3,33 \pm 4,29 \\
7,69(1 / 13) \\
\end{array}$ & $\begin{array}{c}1,25 \pm 0,45^{\mathrm{a}, \mathrm{b}} \\
1,22 \pm 0,44 \\
1,29 \pm 0,49^{\mathrm{a}, \mathrm{b}} \\
156,38 \pm 82,98^{\mathrm{b}} \\
24,12 \pm 0,50^{\mathrm{a}} \\
1,43 \pm 0,55 \\
43,75(7 / 16) \\
4,13 \pm 4,87 \\
14,29(1 / 7) \\
\end{array}$ & $\begin{array}{c}1,00 \pm 0,00^{\mathrm{b}} \\
1,00 \pm 0,00 \\
1,00 \pm 0,00^{\mathrm{b}} \\
159,70 \pm 85,54^{\mathrm{b}} \\
12,64 \pm 1,68^{\mathrm{b}} \\
1,09 \pm 0,62 \\
60,0(6 / 10) \\
6,00 \pm 5,16 \\
33,33(2 / 6) \\
\end{array}$ \\
\hline
\end{tabular}

\footnotetext{
${ }^{3}$ Nutriage® - Guabi;

${ }^{4}$ Centauro® - Guabi;

${ }^{5}$ Statistical Analysis System - versão 5.0 (Microsoft ${ }^{\circledR}$ )
} 
possui grande preocupação com a redução dos custos e com o aumento da produtividade. A diminuição do número de inseminações artificiais ou de coberturas para se obter um produto, além de diminuir os gastos com material, tempo e mão-de-obra especializada, proporciona também a economia do garanhão por reduzir o número de cobrições durante a estação de monta (Brandão, 2001).

\section{Efeito da idade sobre a taxa de perda embrionária de éguas}

A idade média das éguas entre os diferentes tratamentos teve diferença estatística $(p<0,05)$ para os diferentes grupos experimentais. Entretanto, apesar de não mostrar distribuição homogênea entre os tratamentos, os resultados da taxa de concepção para os diferentes intervalos de palpação ( $P 1$ e P2) e garanhões ( $G 1$ e $G 2$ ) não foram influenciados $(p>0,05)$ pela idade da égua.

A idade média das éguas para os grupos P1G1, P2G1, P1G2 e P2G2 foi de $104,56 \pm 47,46,116,73 \pm 65,80,156,38 \pm 82,98$ e 159,70 $\pm 85,54$ meses, respectivamente (Tabela 1). A idade média do grupo P1G1 diferiu $(p<0,05)$ dos grupos P1G2 e P2G2, mas não do grupo P2G1. Vale ressaltar que não houve diferença $(p>0,05)$ entre os grupos dos intervalos de palpação para um mesmo garanhão, mas sim, entre os garanhões. Desta forma, poder-se-ia esperar diferença nos parâmetros reprodutivos entre os dois garanhões, mas não entre os dois intervalos de palpação. Contudo, não foram encontradas diferenças $(p>0,05)$ tanto entre os garanhões quanto entre os intervalos de palpação retal.

Poderia ser esperado que os grupos P1G2 e P2G2 apresentassem maior taxa de perda embrionária, já que eram compostos por éguas com idade média de 13 anos. Isto porque, segundo Hearn et al. (1993), a taxa de perda embrionária aumenta em éguas a partir desta idade. Considera-se que éguas mais velhas possuam pior qualidade do ambiente uterino, uma vez que o útero se localiza anormalmente em uma posição cranioventral no abdômen como resultado da perda do suporte estrutural caudal do trato reprodutivo e o estiramento do ligamento largo do útero. Estes eventos prejudicam a eliminação do conteúdo uterino devido à ineficiência ou modificação no padrão de propagação e intensidade da contração miometrial, que impedem o satisfatório esvaziamento uterino nesses animais (LeBlanc, 2003).
A redução da contratilidade uterina pode dificultar a eliminação de bactérias e corpos estranhos do útero, aumentando a incidência de endometrites e acumulando exsudato inflamatório intra-uterino (Carnevale e Ginther, 1992). Éguas mais velhas também possuem maior grau de degeneração vascular endometrial, como elastose, fibrose, fibroelastose, fibrose perivascular e processos de calcificação que contribuem com os distúrbios na drenagem uterina e, conseqüentemente, levam à persistência de edema endometrial, formando lacunas linfáticas. Isto também contribui para o atraso na limpeza uterina (LeBlanc, 2003).

Apesar dos dados citados, isto não foi confirmado no presente experimento, já que a taxa de concepção e das perdas embrionárias, entre os tratamentos, não diferiram $(p>0,05)$ em função da idade da égua. No presente trabalho, todas as perdas embrionárias ocorreram entre o intervalo do $30^{\circ}$ e o 40 ㅇa de gestação, na freqüência de $11,10 \%$ (1/9) para P1G1, $7,69 \%$ (1/13) para P2G1, 14,29\% (1/7) para P1G2 e 33,33\% $(2 / 6)$ para P2G2, não diferindo $(p>0,05)$ entre tratamentos (Tabela 1).

\section{Taxa de concepção total e por ciclo estral de éguas mestiças submetidas a dois regimes de palpação diária}

No presente experimento, as taxas de gestação no primeiro, segundo e terceiro ciclos estrais foram de: $29,41 \%(5 / 17)$ e $50 \%(4 / 8)$ para o tratamento P1G1; $25 \%(5 / 20), 54,54 \%(6 / 11)$ e $100 \%$ (2/2) para o tratamento P2G1; 41,66\% (5/12) e 50\% (2/4) para o tratamento P1G2; e 60\% (6/10) para o tratamento P2G2, respectivamente. A taxa total de concepção por ciclo foi, para os mesmos grupos, de 36\% (9/25), 39,40\% (13/33), $43,75 \%(7 / 16)$ e $60,0 \%$ (6/10), respectivamente (Tabela 2). As taxas de concepção total, para estes mesmos grupos, foram de $52,90 \%, 65 \%, 58,30 \%$ e $60 \%$. Todos os tratamentos tiveram menos de dois ciclos estrais por gestação: 1,44 $\pm 0,53$ (P1G1), $1,77 \pm 0,73$ (P2G1), 1,29 \pm 0,49 (P1G2) e 1,00 $\pm 0,00$ (P2G2).

As taxas de concepção total e por total de ciclo estral, apresentadas na Tabela 2, não diferiram $(p>0,05)$ pelo teste Exato de Fisher, tanto para os intervalos de palpação (12 e 24 horas) quanto para os garanhões. Desta forma, os dados foram agrupados levando-se apenas em consideração a freqüência de palpação retal (Tabela 3).

Tabela 2: Taxa de gestação por éguas cobertas, após a ovulação, por dois garanhões, seguindo o regime de duas ou uma palpação diária

\begin{tabular}{|c|c|c|c|c|c|c|c|c|}
\hline \multirow[b]{3}{*}{ Ciclo Estral } & \multicolumn{4}{|c|}{ Intervalo de palpação para o Garanhão 1} & \multicolumn{4}{|c|}{ Intervalo de palpação para o Garanhão 2} \\
\hline & \multicolumn{2}{|c|}{24 horas (P1G1) } & \multicolumn{2}{|c|}{12 horas (P2G1) } & \multicolumn{2}{|c|}{24 horas (P1G2) } & \multicolumn{2}{|c|}{12 horas (P2G2) } \\
\hline & $\begin{array}{l}N^{\circ} \text { de } \\
\text { ciclos }\end{array}$ & $\begin{array}{c}\text { Taxa de } \\
\text { Concepção }\end{array}$ & $\begin{array}{l}N^{\circ} \text { de } \\
\text { ciclos }\end{array}$ & $\begin{array}{c}\text { Taxa de } \\
\text { Concepção }\end{array}$ & $\begin{array}{l}\text { № de } \\
\text { ciclos }\end{array}$ & $\begin{array}{c}\text { Taxa de } \\
\text { Concepção }\end{array}$ & $\begin{array}{l}\text { № de } \\
\text { ciclos }\end{array}$ & $\begin{array}{c}\text { Taxa de } \\
\text { Concepção } \\
\end{array}$ \\
\hline $1^{0}$ & $17(5)^{*}$ & $29,41 \%$ & $20(5)^{*}$ & $25,00 \%$ & $12(5)^{\star}$ & $41,66 \%$ & $10(6)^{\star}$ & $60,00 \%$ \\
\hline $2^{\circ}$ & $8(4)^{\star}$ & $50,00 \%$ & $11(6)^{*}$ & $54,54 \%$ & $4(2)^{*}$ & $50,00 \%$ & -- & -- \\
\hline $3^{\circ}$ & -- & -- & $2(2)^{*}$ & $100,00 \%$ & -- & -- & -- & -- \\
\hline Total/Ciclos & $25(9)^{*}$ & $36,00 \%$ & $33(13)^{*}$ & $39,40 \%$ & $16(7)^{\star}$ & $43,75 \%$ & $10(6)^{\star}$ & $60,00 \%$ \\
\hline $\begin{array}{l}\text { Taxa de } \\
\text { Concepção } \\
\text { Total }\end{array}$ & \multicolumn{2}{|c|}{$52,9 \%(9 / 17)$} & \multicolumn{2}{|c|}{$65 \%(13 / 20)$} & \multicolumn{2}{|c|}{$58,3 \%(7 / 12)$} & \multicolumn{2}{|c|}{$60 \%(6 / 10)$} \\
\hline
\end{tabular}

${ }^{*} №$ entre parênteses refere-se às éguas gestantes. A taxa de concepção por ciclo não difere $(p>0,05)$. 
Tabela 3: Taxa de concepção total por ciclo estral de éguas cobertas após a ovulação, segundo o regime de duas ou uma palpação retal

\begin{tabular}{|c|c|c|c|c|}
\hline \multirow[b]{2}{*}{ Ciclo Estral } & \multicolumn{2}{|c|}{ Intervalo de palpação 24 horas } & \multicolumn{2}{|c|}{ Intervalo de palpação 12 horas } \\
\hline & № de ciclos & Taxa de Concepção & № de ciclos & Taxa de Concepção \\
\hline $1^{0}$ 은 & $29(10)^{*}$ & $34,48 \%$ & $30(11)$ & $36,67 \%$ \\
\hline $2^{\circ}$ & $12(6)$ & $50,00 \%$ & $11(6)$ & $54,55 \%$ \\
\hline $3^{\circ}$ & -- & -- & $2(2)$ & $100,00 \%$ \\
\hline \multirow[t]{2}{*}{ Total/Ciclo } & $41(16)$ & $39,02 \%$ & $43(19)$ & $44,19 \%$ \\
\hline & $\mathrm{N}^{0}$ de Éguas & Taxa de Concepção & $\mathrm{N}^{\circ}$ de Éguas & Taxa de Concepção \\
\hline Total/Égua & $29(16)$ & $55,17 \%$ & $30(19)$ & $63,3 \%$ \\
\hline
\end{tabular}

* № entre parênteses refere-se às éguas gestantes. A taxa de concepção por ciclo não diferiu ( $p>0,05)$, pelo teste Exato de Fisher ou Qui-quadrado, independente do garanhão

É difícil realizar uma comparação dos dados obtidos neste experimento em relação aos dados da literatura, devido à utilização de diferentes metodologias de inseminações artificiais ou monta natural, diferentes intervalos de cobrição em relação ao momento da ovulação e diferentes maneiras de utilização do sêmen (fresco, fresco-diluído, resfriado ou congelado), além de outras variáveis a se considerar, tais como a fertilidade das éguas e dos garanhões utilizados.

Levando-se em consideração apenas a relação dos intervalos de palpação sobre a taxa de concepção, o presente experimento obteve $39,02 \%$ (16/41) para o intervalo de 24 horas e 44,19\% (19/43) para o intervalo de 12 horas, utilizandose o número total de ciclos estrais, e 55,17\% (16/29) e $63,3 \%$ (19/30) ao considerar o número total de éguas. Estes resultados são semelhantes aos obtidos por Palmer (1984; $47,00 \%)$ e Silva $(1995 ; 36,50 \%)$ para taxa de concepção por ciclo, e de Zivotikov (1940; 34,70\%) e Skatkin (1943; 39,00\%) para taxa de concepção total em coberturas realizadas até 12 horas após a ovulação.

Poucos são os trabalhos que, utilizando coberturas após a ovulação, obtiveram bons resultados e, dentre estes, se destacam os trabalhos de Allen (1981) e Belling (1984), realizados sob diferentes condições. Em 1980, Allen (1981) utilizou 17 fêmeas cobertas após a ovulação, por apenas um garanhão, e obteve taxa de concepção total de $76 \%$, com 1,2 ciclos/concepção. Já Belling (1984) utilizou grande número de cobrições após a ovulação, em 12 rebanhos particulares. Durante um período de sete anos, o autor supervisionou o cruzamento de 355 éguas dentro de 24 horas após a ovulação. Os resultados das cobrições após a ovulação foram computados utilizando-se o número de serviços/concepção e índice total de concepção. Foram necessários 425 serviços para obter 293 gestações e ao final do quarto ciclo estral a taxa de concepção total foi de $82,53 \%$ (293/355). Deve-se aqui ressaltar que os valores encontrados para taxa de gestação total, no presente estudo de $55,17 \%$ (16/29) para o intervalo de até 24 horas e de 63,3\% (19/30) para o intervalo de até 12 horas da ovulação, foram obtidos com a utilização de apenas dois ciclos estrais por égua, salvo dois animais que foram cobertos até o terceiro ciclo estral.

A maior parte dos trabalhos citados na literatura faz menção às inseminações ou coberturas realizadas até 12 horas após a ovulação. Os trabalhos que realizaram coberturas em intervalos superiores a 12 horas mencionam queda da fertilidade. Palmer (1984), realizando duas palpações transretais diárias, em 34 éguas inseminadas com sêmen a fresco, observou queda drástica da fertilidade/ciclo quando o intervalo da ovulação à inseminação passou de 0-12 horas (8/17 - 47\%) para o período de 12-24 horas (3/17 - 18\%).
Frente aos resultados da literatura acima descritos, seriam esperadas diferenças nas taxas de concepção das coberturas realizadas até 24 (P1) e 12 horas (P2) após a ovulação. Contudo, no presente experimento, isto não ocorreu $(p>0,05)$. Hunter (1990) sugere que a homogeneidade entre as respostas de éguas cobertas 12 ou 24 horas após a ovulação se dá pelo fato do oócito, ocasionalmente, poder ser liberado no estádio de desenvolvimento primário, secundário ou até mesmo num estado intermediário, condição variável entre animais e entre ciclos estrais. Tal variação, na égua, poderia ser atribuída à falta do pico pré-ovulatório de LH, diferente de outras espécies (ovelha, vaca e porca). Dessa forma, o oócito primário ovulado na forma imatura poderia continuar à meiose na tuba uterina, o que daria maior viabilidade, antes do início do processo degenerativo, quando comparado com oócitos ovulados em estádio secundário (Hunter, 1990).

Apesar de, aparentemente, a viabilidade do oócito ter garantido a homogeneidade $(p>0,05)$ dos valores da taxa de concepção total por ciclo, $44,19 \%$ (19/43) e $39,02 \%$ (16/41) e por égua, $63,3 \%$ $(19 / 30)$ e $55,17 \%$ (16/29), para as coberturas realizadas dentro do intervalo de 12 horas e 24 horas, respectivamente, após ovulação, consideram-se esses valores como baixos, quando comparados com os trabalhos de Allen (1981-76-100\%), Belling $(1984-80,82 \%)$ e Koskinen (1990 - 100\%) que realizaram coberturas a intervalos de até 12 horas após a ovulação.

Apesar de todas essas prerrogativas, o resultado da taxa de concepção total do presente estudo foi obtido de dois ciclos estrais por égua. Assim, pode-se especular que o maior número de serviços por égua geraria uma maior taxa de concepção final, independentemente do intervalo de palpação, como obtido por Belling $(82,53 \%, 1984)$ após o quarto serviço.

\section{Conclusões}

A partir dos resultados obtidos, pode-se concluir que:

- Coberturas realizadas após a ovulação, a intervalos de palpação de até 24 horas, na espécie eqüina, mostram-se viáveis;

- A menor taxa de concepção de éguas cobertas 24 ou 12 horas após a ovulação não foi associada diretamente à idade da égua ou do garanhão;

- Estratégias de manejo de palpação transretal, a cada 12 ou 24 horas, podem ser utilizadas como alternativa para assegurar bons índices de fertilidade, a partir de garanhões ou éguas limitados para esta função. 


\section{Referências}

ALLEN, W. E. Fertility in pony mares after post ovulation service. Equine Veterinary Journal, v. 13, n. 2, p.134-135, 1981.

BELLING, T. H. Postovulation breeding and related reproductive phenomena in the mare. Equine Practice, v. 6, n. 6, p. 12-19, 1984.

BRANDÃO, F.Z. Efeito da concentração espermática e do intervalo entre as duas últimas inseminações sobre a fertilidade de éguas inseminadas com sêmen a fresco diluído. 2001.94 f. Dissertação (Mestrado em Medicina Veterinária) Escola de Veterinária UFMG.

CARNEVALE, E. M.; GINTHER, O. J. Relationship of age to uterine function and reproductive efficiency in mares. Theriogenology, v. 37, n. 5, p. 1101-1115, 1992.

HEARN, P.; BONNETT, B.; SAMPER, J. Factors influencing pregnancy and pregnancy loss on one thoroughbred farm. American Association of Equine Practitioners, annual convention, v. 39, p. 161-162, 1993

HUNTER, R. H. F. Gamete lifespans in the mare's genital tract. Equine Veterinary Journal, v. 22, n. 6, p. 378-379, 1990.

iROIG, J. M. ; MUÑOZ, F.; PIEDRAFITA, J.; et al. Prediction of the day of ovulation in mares through physiological parameters measured during estrous. Revista Científica, v. 14, p. 1-8, 2005. Disponível em: file://

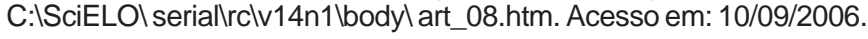

JACOB, J. C. F.; ALBUQUERQUE, F. T.; DOMINGUES, M. B.; et al. Taxa de gestação em éguas mangalarga marchador inseminadas pósovulação. Revista Brasileira de Reprodução Animal, v. 24, n. 1, p. 5155,2000 .
KOSKINEN, E.; LINDEBERG, H.; KUNTSI, H.; et al. Fertility of mares after postovulatory insemination. Zentralb/ Veterinarmed A. v. 37, n. 1, p. 77-80, 1990. Pubmed - Abstract. Disponível em: http:// www.ncbi.nlm.nih. gov/entrez/query.fcgi?C MD=search\&DB= pubmed. Acesso em: 19/08/2006.

LeBLANC, M. M. Persistent mating induced endometritis in the mare: pathogenesis, diagnosis and treatment. In: Recent Advances in Equine Reproduction, B.A. Ball (Ed.) Publisher: International Veterinary Information Service (www.ivis.org), Ithaca, New York, USA, 2003.

PALMER, E. Factors affecting stallion semen survival and fertility. Tenth International Congress Animal Reproduction Arte Insemination II, p. 377-379, 1984.

PICKETT, B. W.; SQUIRES, E. L.; McKINNON, A. O. Procedures of collections, evaluation and utilization of stallion semen for artificial insemination. Fort Collins: Colorado Stade University, Animal Reproduction Laboratory, 1987, $125 \mathrm{p}$.

SILVA, M. D. Influência de dois sistemas de cobrição após a ovulação, sobre a fertilidade de éguas, reabsorção embrionária e sexo dos produtos. 1995. 59 f. Dissertação (Mestrado em Medicina Veterinária). Belo Horizonte: UFMG, Escola de Veterinária.

SKATKIN, P.N. Systems of mating and artificial insemination of horses. Animal Breeding Abstracts, v. 11, n. 2, p. 86, 1943. (Abstract).

ZIVOTIKOV, H. I. The efficacy of mating and insemination of mares during or after ovulation. Sovetsk. Zootech, n. 1, p. 108-109, 1940. Animal Breeding Abstract, v. 9, n. 4, p. 303, 1941 (Abstract). 